\title{
CARTOGRAFIA E SIMBOLOGIA GEOMORFOLÓGICA: EVOLUINDO DA CARTOGRAFIA TRADICIONAL PARA O USO DE SIMBOLOGIA DIGITAL
}

Sílvio Carlos Rodrigues

Doutor em Geografia Física - Instituto de Geografia - Universidade Federal de Uberlândia - Av. João Naves de Avila, 2121 Bloco 1 H Sala 16 - CEP 38400-902 - Uberlândia-MG - e-mail: silgel@ufu.br

\section{Resumo}

Este trabalho pretende discutir formas de promover a uniformização de símbolos utilizados na cartografia geomorfológica, baseando-se principalmente no sistema ITC, gerando padrões de informação entre os profissionais da área em questão e afins, além de facilitar a representação de feições do modelado e de processos morfodinâmicos das unidades geomorfológicas. Portanto, é apresentada uma sugestão de construção de linhas (linetypes) no software gráfico AutoCad, que tende a prontificar o uso de símbolos lineares digitais e otimizar o trabalho cartográfico por meio do emprego de símbolos já utilizados na cartografia geomorfológica.

Palavras-chave: cartografia geomorfológica, simbologia geomorfológica, Sistema ITC

\begin{abstract}
This paper's objectives are discuss ways of promoting just one kind of symbols group that have to be used on geomorphologic cartography, having its bases related mainly with the ITC System. So, a standardization will be done and the professionals will start to work just with a way, making the map visualization easier. For this, the paper shows a line construction suggestion using the software AutoCad, what will help in the process of standardization of the geomorphologic cartography.
\end{abstract}

Keywords: geomorphologic cartography, geomorphological symbols, ITC System

\section{Introdução}

Por definição, a ciência geomorfológica identifica, classifica e analisa as formas da superfície terrestre, buscando compreender as relações processuais pretéritas e atuais do relevo planetário em seus diversos aspectos genéticos, cronológicos, morfológicos, morfométricos e dinâmicos (RODRIGUES, 1998). Associada a classificação e análise pressupõe-se ainda, uma descrição sobre o modelado e uma avaliação dos complexos físicos e físico-biológicos considerando-se também, a estrutura geológica e os processos morfoclimáticos atuantes ao longo do tempo.
Nesse sentido, intimamente ligado à interpretação dos dados competentes à Geomorfologia, é atribuído à Cartografia Geomorfológica o papel de recurso gráfico, sendo citada por Ferreira (2003) como "uma importante ferramenta nos estudos ambientais e no planejamento físico-territorial, gerando subsídios para o entendimento dos ambientes naturais.". Assim sendo, pode-se afirmar que o trabalho de cartografia geomorfológica deve ser apoiado em critérios de representação gráfica bem definidos, a fim de otimizar a leitura e facilitar a interpretação dos fenômenos geomorfológicos. Sobre a ordenação dos procedimentos durante a elaboração de um mapeamento geomorfológico, Ross (1992) faz as seguintes considerações: 


\begin{abstract}
"A cartografação geomorfológica deve mapear concretamente o que se vê e não o que se deduz da análise geomorfológica, portanto em primeiro plano os mapas geomorfológicos devem representar os diferentes tamanhos de formas de relevo, dentro da escala compatível. Em primeiro plano deve-se representar as formas de diferentes tamanhos e em planos secundários, a representação da morfometria, morfogênese e morfocronologia, que têm vínculo direto com a tipologia das formas".
\end{abstract}

Assim, podemos concluir que o processo de mapeamento compreende desde os levantamentos e observações diretas no campo, técnicas de representação cartográfica, análise de documentação, linguagem visual, até a interpretação, publicação e impressão definitiva do mapa. Ainda sobre o mapeamento geomorfológico Tricart (1965) (apud ROSS, 1996) afirma que este "constitui a base da pesquisa e não a concretização gráfica de pesquisa já feita”, servindo ao mesmo tempo nesse caso, como um instrumento de direcionamento e, quando concluído, síntese/produto da mesma. (Rodrigues, 1998, Souza, 2006)

A questão temporal apresenta-se como uma variável que a cartografia geomorfológica e os estudos geomorfológicos enfocam com dificuldade. Nos trabalhos que abrangem grandes superfícies, a questão temporal é avaliada dentro da escala geológica do tempo. Nos estudos mais localizados, este problema torna-se mais grave, pois a escala do tempo geológico nem sempre satisfaz o enfoque adotado, sendo difícil adotar outros intervalos menores de tempo envolvidos nos processos ou na esculturação do relevo de determinadas áreas.

Tentando resolver esta questão Tricart (op. cit.) apresenta uma proposta de classificação taxonômica dos fatos geomorfológicos na qual as unidades de superfície têm correspondência com diferentes escalas temporais. Esta classificação associa diferentes unidades da superfície da Terra a diferentes unidades espaço-temporais (Tabela 1).

\section{Tabela 1 - Tabela Sinótica. Classificação Taxonômica dos Fatos Geomorfológicos.}

\begin{tabular}{|c|c|c|c|c|}
\hline $\begin{array}{l}\text { Unidade } \\
\mathrm{em} \mathrm{km}^{2}\end{array}$ & Características das Unidades, exemplos & Unidades climáticas correspondentes & $\begin{array}{c}\text { Mecanismos genéticos que comandam } \\
\text { o relevo }\end{array}$ & $\begin{array}{l}\text { Ordem de } \\
\text { grandeza } \\
\text { temporal }\end{array}$ \\
\hline $10^{8}$ & $\begin{array}{l}\text { Continentes, Bacias Oceânicas } \\
\text { (configuração do Globo) }\end{array}$ & $\begin{array}{l}\text { Grandes conjuntos zonais comandados pelos } \\
\text { fatores astronômicos }\end{array}$ & \begin{tabular}{|l|l|}
$\begin{array}{l}\text { Diferenciação da crosta terrestre, Sial e } \\
\text { Sima }\end{array}$ \\
\end{tabular} & $10^{9}$ anos \\
\hline $10^{6}$ & $\begin{array}{l}\text { Grandes conjuntos estruturais (Escudo } \\
\text { Escandinavo, Bacia do Congo) }\end{array}$ & $\begin{array}{l}\text { Grandes tipos de climas (interferência de } \\
\text { influências geográficas através de fatos } \\
\text { astronômicos) }\end{array}$ & $\begin{array}{l}\text { Movimentos da crosta terrestre, como } \\
\text { formação de geosinclinais. Influências } \\
\text { climáticas sobre a dissecação }\end{array}$ & $10^{8}$ anos \\
\hline $10^{4}$ & $\begin{array}{l}\text { Grandes unidades estruturais (Bacia de } \\
\text { Paris, Maçico do Jura, Maçico Central) }\end{array}$ & $\begin{array}{l}\text { Nuances dentro dos tipos climáticos, mas } \\
\text { com pequena importância para a dissecação }\end{array}$ & \begin{tabular}{|l|} 
Unidades tectônicas que podem ter \\
ligações com a paleogeografia. \\
Velocidade de dissecação influenciada \\
pela litologia
\end{tabular} & $10^{7}$ anos \\
\hline $10^{2}$ & $\begin{array}{l}\text { Unidades tectônicas elementares: } \\
\text { maçicos, montanhas, horts e fossas }\end{array}$ & $\begin{array}{l}\text { Climas regionais influenciados } \\
\text { geograficamente sobretudo nas regiões } \\
\text { montanhosas }\end{array}$ & $\begin{array}{l}\text { Influência predominante da tectônica, } \\
\text { secundariamente da litologia }\end{array}$ & $10^{7}$ anos \\
\hline \multicolumn{5}{|c|}{ Limiar de compensação isostática } \\
\hline 10 & $\begin{array}{l}\text { Acidentes tectônicos: Anticlinais, } \\
\text { sinclinais, montes, vales, etc. }\end{array}$ & $\begin{array}{l}\text { Climas locais, influenciados pela disposição } \\
\text { do relevo: topografia montanhosa }\end{array}$ & $\begin{array}{l}\text { Predomínio da litologia e da } \\
\text { tectoestática. Influências estruturais } \\
\text { clássicas }\end{array}$ & $10^{6}$ a $10^{7}$ anos \\
\hline $10^{-2}$ & $\begin{array}{l}\text { Formas do relevo: terraços, circos e } \\
\text { morainas glaciais, cones de dejecção }\end{array}$ & $\begin{array}{l}\text { Mesoclimas ligados diretamente a forma } \\
\text { (nicho de nivação, por exemplo) }\end{array}$ & $\begin{array}{l}\text { Predominância de fatores } \\
\text { morfodinâmicos, influência da litologia }\end{array}$ & $10^{4}$ anos \\
\hline $10^{-6}$ & $\begin{array}{l}\text { Microformas: depósitos de solifluxão, } \\
\text { solos poligonais, ravinas }\end{array}$ & $\begin{array}{l}\text { Microclima diretamente ligado a forma por } \\
\text { autocatalise (exemplo: lapies) }\end{array}$ & idem & $10^{2}$ anos \\
\hline $10^{-8}$ & $\begin{array}{l}\text { Microscópicas: detalhes de corrosão, } \\
\text { etc. }\end{array}$ & Meios microscópicos & $\begin{array}{l}\text { Interferência da dinâmica e da textura } \\
\text { da rocha }\end{array}$ & \\
\hline
\end{tabular}

Fonte: Adaptado de Principles e Methodes de Geomorphologie, Tricart, J - 1965.

Esta preocupação também é encontrada no trabalho de Mercerjakov (1968) quando analisa o problema de classificação do relevo da Terra. Nesse trabalho é apresentada uma esquematização das morfotecturas, morfoestruturas e morfoesculturas segundo diferentes ordens espaciais, conforme apresentado na Tabela 2.

Porém, nesse trabalho, a questão temporal acaba recebendo uma menor importância do ponto de vista cronológico, passando a estar associada a eventos geológicos que atuam na geração ou esculturação das morfoestruturas.
A questão da representação das formas de relevo apresenta dificuldades quanto a sua concepção e conceituação teórica e técnica. Diversas técnicas são utilizadas para a cartografação do relevo, o trabalho de Salomé \& Van Dorsser (1982) apresenta uma comparação entre seis modelos de representação cartográfica do relevo de uma mesma área, mostrando e comparando os diferentes resultados obtidos pelas diferentes técnicas. Segundo Ross (1992), “A cartografia geomorfológica ressente-se da dificuldade de encontrar adequado mo- 
delo de representação gráfica, existindo uma diversidade de propostas metodológicas, que valorizam sempre um determinado elemento do relevo". Este também é o resultado a que chegam Salomé \& Van Dorsser, atra- vés da experiência citada acima, pois cada um dos modelos de representação acaba seguindo preferencialmente uma ou outra linha de sustentação teóricometodológica.

\section{Tabela 2 - Esquema Geral de Classificação do Relevo da Terra}

\begin{tabular}{|c|c|c|c|}
\hline $\begin{array}{c}\text { Superficie } \\
\mathrm{em} \mathrm{km}^{2}\end{array}$ & \begin{tabular}{|c|}
$\begin{array}{c}\text { Elementos Morfoestruturais (morfotectônica } \\
\text { do Relevo de continentes e depressões } \\
\text { oceânicas) }\end{array}$ \\
\end{tabular} & $\begin{array}{l}\text { Categorias Morfoesculturais do Relevo } \\
\text { (Terra Firme) }\end{array}$ & $\begin{array}{l}\text { Categorias Morfoesculturais do Relevo } \\
\text { (Fundo dos Oceanos e Mares) }\end{array}$ \\
\hline $10^{7}$ a $10^{6}$ & $\begin{array}{l}\text { Morfotecturas de } 1^{\mathrm{a}} \text { ordem-massa continentais } \\
\text { (incluindo as plataformas continentais) } \\
\text { depressões oceânicas }\end{array}$ & \multirow{2}{*}{$\begin{array}{l}\text { Zonas morfoesculturais (morfoclimáticas) } \\
\text { zonas de morfoesculturas criogênica } \\
\text { glacial, fluvial, árida e outras }\end{array}$} & \multirow{2}{*}{$\begin{array}{l}\text { Zonas morfoesculturais: } \\
\text { - zonas circumpolares de formas glaciais } \\
\text { - zonas de altitudes temperadas } \\
\text { - zonas tropicais e equatoriais }\end{array}$} \\
\hline $10^{6}$ a $10^{5}$ & $\begin{array}{l}\text { Morfotecturas de } 2^{\mathrm{a}} \text { ordem planos de } \\
\text { plataforma, zonas montanhosas (orogênicas) }\end{array}$ & & \\
\hline $10^{5}$ a $10^{3}$ & $\begin{array}{l}\text { Morfoestruturas de } l^{\text {a }} \text { ordem - planaltos, } \\
\text { baixas regiões planas, cadeias de montanhas, } \\
\text { depressões extensas, etc. }\end{array}$ & $\begin{array}{l}\text { Províncias morfoesculturais províncias de } \\
\text { morfoesculturas fluvial de tipo } \\
\text { Mediterrâneo, províncias de erosão glacial } \\
\text { provincias de acumulacão etc. }\end{array}$ & \\
\hline $10^{3}$ a $10^{2}$ & $\begin{array}{l}\text { Morfoestruturas de } 2^{\mathrm{a}} \text { ordem - bombeamentos } \\
\text { tectônicos marcados no relevo depressões } \\
\text { tectônicas, etc. }\end{array}$ & $\begin{array}{l}\text { Regiões morfoesculturais de morainas } \\
\text { frontais, regiões de relevo cárstica etc }\end{array}$ & \\
\hline $10^{2}$ a 10 & $\begin{array}{l}\text { Morfoestruturas de } 3^{\text {a }} \text { ordem - anticlinais } \\
\text { marcadas no relevo, fossas recentes, } \\
\text { cumeadas, etc. }\end{array}$ & $\begin{array}{l}\text { Formas particulares do relevo determinadas } \\
\text { sobretudo pelos fatores exogenéticos Vales } \\
\text { fluviais, formas cársticas, etc. }\end{array}$ & $\begin{array}{l}\text { Vales submarinos, formas de acumulação de } \\
\text { icebergs. }\end{array}$ \\
\hline 10 a $10^{-1}$ & Microrelevo tectônico diques, fendas. & $\begin{array}{l}\text { Pequenas formas de relevo de origem } \\
\text { exógena. } \\
\text { Solos poligonais, pequenos hidrolacólitos }\end{array}$ & \\
\hline
\end{tabular}

Fonte: Adaptado de I.P. Mercerjakov - Les concepts de Morphostruture et Morphoesculture. Paris, Annales de Geographie, 1968

Seguindo recomendação da Demek (1998) a cartografia geomorfológica deve apresentar necessariamente quatro níveis de abordagem. Assim, devem ser anotados a morfometria (altimetria, dimensões, desníveis, extensões); a morfologia (formas do perfil, convexidades, concavidades, retilinidades, topos, rupturas, fundos de vale, etc); a gênese (agradação ou degradação); a cronologia relativa (datação absoluta, idade relativa das formas) e o comportamento morfodinâmico.
Alguns autores preocuparam-se em estabelecer uma hierarquização dos elementos do relevo segundo escalas espaciais, como Tricart (Tabela 1), Mercerjakov (Tabela 2), e outros, classes de cartografação e suas relações com as escalas de representação, como o caso de Thomas e Young (apud Faniran \& Jeje) (Tabela 3).

Tabela 3 - Hierarquia das Paisagens, conforme Proposto por Thomas e Young.

\begin{tabular}{|c|c|c|c|c|}
\hline $\begin{array}{l}\text { Ordem de } \\
\text { paisagem }\end{array}$ & $\begin{array}{c}\text { Unidade de } \\
\text { Paisagem de } \\
\text { Thomas }\end{array}$ & $\begin{array}{c}\text { Unidade da } \\
\text { Paisagem de } \\
\text { Young }\end{array}$ & $\begin{array}{l}\text { Escala de } \\
\text { Mapeamento }\end{array}$ & Exemplos \\
\hline 1 & Posição Local & $\begin{array}{c}\text { Unidade de } \\
\text { Vertente }\end{array}$ & 1:10.000 & Uma unidade de vertente com gradiente ou curvaturas uniformes \\
\hline 2 & Faceta & & $1: 25.000$ & $\begin{array}{l}\text { Dois ou mais segmentos de vertentes formando uma feição definitiva, } \\
\text { por exemplo, a vertente de um vale, um pedimento, ou uma escarpa }\end{array}$ \\
\hline 3 & $\begin{array}{l}\text { Unidade de } \\
\text { paisagem }\end{array}$ & Paisagem & $1: 50.000$ & $\begin{array}{l}\text { Duas ou mais facetas formando uma feição definitiva, por exemplo, } \\
\text { um inselberg, um vale de um rio, ou uma crista }\end{array}$ \\
\hline 4 & $\begin{array}{l}\text { Paisagem } \\
\text { complexa }\end{array}$ & & $\begin{array}{l}1: 50.000- \\
1.100 .000\end{array}$ & $\begin{array}{l}\text { Duas ou mais unidades de paisagem formando uma feição definitiva, } \\
\text { por exemplo, um relevo de cuesta }\end{array}$ \\
\hline 5 & $\begin{array}{c}\text { Sistema de } \\
\text { paisagens }\end{array}$ & $\begin{array}{c}\text { Unidades de } \\
\text { relevo }\end{array}$ & $\begin{array}{l}1: 1.000 .000- \\
1: 60.000\end{array}$ & $\begin{array}{l}\text { Uma planície ou um grupo de colinas ou um complexo de colinas e } \\
\text { cristas, ou um planalto dissecado }\end{array}$ \\
\hline 6 & $\begin{array}{c}\text { Paisagem } \\
\text { regional }\end{array}$ & $\begin{array}{c}\text { Maiores } \\
\text { unidades de } \\
\text { relevo }\end{array}$ & $\begin{array}{l}1: 500.000 \text { ou } \\
\text { maiores }\end{array}$ & Um sistema montanhoso dobrado \\
\hline
\end{tabular}

Fonte: Adaptado de Faniram A. \& Jeje, L.K.(1980) - Humid Tropical Geomorphology

Gellert (apud Demek, 1972) mostra com esta classificação que os mapas geomorfológicos possuem um grande potencial de aplicação prática, podendo ser confeccionados conforme alguns direcionamentos específicos.

\section{Da Cartografia Analógica à Cartografia Digital}

A partir da década de 1970, com o surgimento e crescente ampliação do uso de microcomputadores, a ciência 
cartográfica passou a se dedicar à automação do desenho. A partir desse momento a Cartografia Analógica passa a contar com a tecnologia do Geoprocessamento apoiada em softwares e hardwares cada vez mais sofisticados integrando as bases de informação alfa-numérica com a informação gráfica de determinado espaço correspondendo a Cartografia Digital. (Souza et al, 2004, p 136)

A automação dos mapas, por sua vez, também influenciou diretamente na Simbologia Gráfica (convenções) pelas novas possibilidades de representação simbológica permitida pelos softwares de desenho. As variáveis visuais do sistema de símbolos da linguagem cartográfica tradicional foram gradativamente substituídas por cor e hachuras representadas por pontos, linhas e polígonos vetorizados. (Souza et al, 2004, p 137)

Neste caminho, a aplicação de técnicas de Semiologia Gráfica para a visualização de dados é um pressuposto da Cartografia moderna, principalmente, no que diz respeito aos métodos condicionados a um sistema integrado de ferramentas SIG, que possibilitam a manipulação, armazenamento, representação gráfica e a análise das informações. (Souza et al, 2004, p 137)

Tendo como base as variáveis visuais utilizadas na simbologia, a execução de um documento cartográfico deve seguir precisamente a linguagem da Semiologia Gráfica, tendo sempre como objetivo a finalidade de um mapa, que está diretamente associada à informação e à transmissão de conhecimentos. A partir de então, sugere-se a precisão e a prudência no uso dos símbolos, para que seus usuários assimilem os dados cartográficos e utilizem as informações da forma mais adequada. (Souza et al, 2004, p 138)

\section{Geomorfologia apoiada na cartografia digital}

A Geomorfologia, nas últimas décadas, tem apresentado novas técnicas metodológicas com uma roupagem atualizada dos parâmetros conceituais e uma base tecnológica apoiada nas ferramentas informatizadas, objetivando a aplicação do conhecimento geomorfológico de forma eficaz aos estudos e manejos ambientais.

Tradicionalmente os mapas geomorfológicos registravam as feições geomorfológicas de uma área de forma descritiva, baseando-se em sistema classificatório específico e sem a preocupação de apresentar elementos cujo interesse estivesse associado a problemas ambientais. Este procedimento dava a estes mapas um valor prático direto pouco útil, por exemplo, para o planejamento ambiental.

Os mapas geomorfológicos assim concebidos começaram a ser produzidos a partir da Segunda Guerra Mundial, sendo considerado como um método fundamental para a análise das formas do relevo. Entre as décadas de 1940 e 1970 vários sistemas classificatórios aplicados ao mapeamento das formas do relevo foram testados, em alguns países da Europa tais como a Holanda, Bélgica, Polônia, França e Suíça (Salome \& Van Doorser, 1982).

Segundo Rosa, (apud SIQUEIRA, 1998):

\begin{abstract}
“A forma do relevo é de fundamental importância no estudo das paisagens. As informações topográficas são indispensáveis, devendo ser representadas de forma precisa, clara, simples e por meio de uma simbologia elaborada de modo a aproximar-se ao máximo das formas existentes no espaço geográfico e a facilitar a sua leitura e interpretação. Devem também ser quantificadas, de modo a permitir a avaliação e interpretação correta do modelado".
\end{abstract}

Atualmente nota-se nas propostas metodológicas de mapeamento a proposição orientada para retratar os mapas geomorfológicos com informações de interesse às necessidades de um planejamento. A questão da cartografia e representação das formas de relevo apresenta dificuldades em relação a sua concepção e conceituação teórica e técnica. Diversas metodologias são utilizadas na cartografação do relevo.

Atualmente, um importante aspecto a se considerar quanto à utilização de Sistemas de Informação Geográfica em mapeamentos geomorfológicos é a carência de modelos de convenções cartográficas otimizadas, ou seja, necessárias no ato da vetorização das bases. Tal deficiência é ainda mais clara quando se procura nos softwares utilizados, linhas específicas para representação de feições geomorfológicas. (Souza, 2006)

Assim sendo, o objetivo principal desse trabalho é o emprego do software AutoCAD no desenvolvimento de simbologia para utilização na cartografia geomorfológica digital sendo que os pressupostos teóricos estão fundamentados no Sistema ITC para Levantamentos Geomorfológicos - "ITC textbook" (VERSTAPPEN \& VAN ZUIDAM, 1975), onde são apresentadas convenções geomorfológicas e geológicas básicas.

Segundo Brito \& Rosa (1994), "um CAD possui funções que permitem a representação precisa de linhas e formas, podendo ser utilizado na digitalização de mapas e cartas”. No entanto, apresenta restrições no que diz respeito à atribuição de outras informações às entidades espaciais. Apesar disso, os CADs podem ser utilizados em conjunto com os SIGs, representando uma importante ferramenta no auxílio à digitalização gráfica.

Nesse sentido, o presente trabalho procura suprir a carência de estudos mais detalhados a cerca do desenvolvimento e aperfeiçoamento de linhas especiais para utilização como simbologia na Cartografia Geomorfológica. 
Sendo os sistemas CAD considerados recursos que contemplam as mais diversas áreas dentre as chamadas geotecnologias, tais estudos atem-se ainda, à problemática da conformidade de convenções adotadas nos trabalhos cartográficos, visto que o uso da informática conseguiu flexibilizar as atividades da cartografia possibilitando o uso de diversas simbologias gráficas, no entanto, facilitou simultaneamente a disseminação de estilos diferenciados, sem padrões definidos.

\section{Metodologia}

A pesquisa em questão propõe-se a investigar e aplicar os métodos de desenvolvimento e aperfeiçoamento das linhas digitais na Cartografia Geomorfológica. O procedimento técnico-operacional utilizado parte do princípio de que, se é possível aperfeiçoar as linhas existentes conhecendo os passos de elaboração, ou seja, os procedimentos de programação utilizados, há também condições de desenvolver símbolos lineares segundo as intenções desejadas.

Nesse caso, o primeiro passo consta de uma revisão bibliográfica a respeito do software, mais especificamente, sobre o tutorial, onde se encontram dados de grande relevância. Com base nas informações adquiridas, buscou-se novos fundamentos nas bibliografias científicas, manuais técnicos de informática (software e hardware), Internet e por meio de contatos com usuários e especialistas no sistema e/ou software CAD.
Sabendo-se que o desenvolvimento obedece a uma linha de programação, foram realizados testes na fase inicial da pesquisa com as linhas já existentes a fim de se verificar as particularidades técnicas relativas à escala de apresentação, rotação e deslocamento em relação à origem dos símbolos e textos dispostos na linha. Os tipos de linhas criados obedeceram basicamente aos padrões do Sistema ITC para Levantamentos Geomorfológicos - "ITC textbook" (VERSTAPPEN \& VAN ZUIDAM, 1975), onde são apresentados símbolos lineares e pontuais geomorfológicos e geológicos para mapas. Os testes foram realizados no Laboratório de Geomorfologia e Erosão dos Solos (LAGES) da Universidade Federal de Uberlândia (UFU). As linhas concluídas foram utilizadas "a priori" em ensaios Cartográficos dentro do próprio LAGES.

\section{Resultados}

\section{Simbologia Desenvolvida para utilização na cartografia Geomorfológica}

A partir dos padrões de símbolos lineares propostos pelo Sistema ITC, principalmente, e em atenção a outras identidades lineares identificadas em mapas geomorfológicos diversos, foram desenvolvidas linhas para utilização na cartografia geomorfológica (quadro 3), utilizando-se das ferramentas e métodos para criação de entidades gráficas lineares (linetypes), disponíveis no software AutoCAD.

Quadro 1 - Linhas desenvolvidas para utilização na cartografia geomorfológica a partir dos padrões de símbolos lineares propostos pelo Sistema ITC entre outros.

\begin{tabular}{|c|c|c|c|}
\hline Tipos & Linetype & Aparência & Representação Gräfica \\
\hline \multirow{5}{*}{$\frac{\frac{\mathrm{e}}{\mathrm{E}}}{\mathrm{E}}$} & $\begin{array}{l}\text { Borda_Eros_- } \\
\text { Moderado }\end{array}$ & _H_ILIL & Formas estruturais do tipo mergulho e direção. \\
\hline & $\begin{array}{l}\text { Borda_Eros__ } \\
\text { Empinado }\end{array}$ & _III_IILIIL & Formas estruturais do tipo mergulho e direção. \\
\hline & Escarpamento & LLLI_L & Formas estruturais do tipo escarpamento. \\
\hline & $\begin{array}{l}\text { Ruptura_de_- } \\
\text { Falha }\end{array}$ & ـL & Modelado de aplanamento de dissecação e/ou dissolução. \\
\hline & Ressalto & -LI_LL & Modelado de aplanamento de dissecação e/ou dissolução. \\
\hline \multirow{6}{*}{ 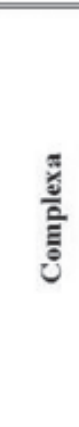 } & $\begin{array}{l}\text { Escarp_Falha_ } \\
\text { Menor }\end{array}$ & _f_LLLLட_ & Formas estruturais do tipo escarpamento de falha menor. \\
\hline & $\begin{array}{l}\text { Linha_de_ } \\
\text { Falha }\end{array}$ & f - . f & Formas estruturais do tipo escarpamento de falha provável. \\
\hline & Falhamento & $\triangle \Delta$ & Formas estruturais do tipo escarpamento de cuesta erodida. \\
\hline & $\begin{array}{l}\text { Borda_Patamar_- } \\
\text { Estrut }\end{array}$ & ㅁㅁ & Formas de origem denudacional. \\
\hline & $\begin{array}{l}\text { Borda_Patamar_ } \\
\text { Kärstico }\end{array}$ & 11 & Formas de origem de dissolução (Karsழ). \\
\hline & $\begin{array}{l}\text { Borda_Eros_- } \\
\text { Horizontal }\end{array}$ & ++++ & Formas estruturais do tipo mergulho e direção horizontal. \\
\hline
\end{tabular}

Adaptado de SOUZA (2006) 
Para melhor elucidar a eficiência e a praticidade da representação gráfica das linetypes desenvolvidas a partir do software CAD, foi analisado e adotado como base para o Ensaio Cartográfico, um mapa geomorfológico gerado a partir do PROJETO
RADAMBRASIL e editado na escala 1:1.000.000 no ano de 1982, mais especificamente, um trecho da Folha SD.23 (Brasília) situado entre as coordenadas geográficas: $13^{\circ} 00^{\prime}$ a $15^{\circ} 00^{\prime}$ de latitude sul e $44^{\circ} 00^{\prime}$ a $46^{\circ} 00^{\prime}$ ' de longitude oeste de Greenwich.

É importante salientar que os símbolos constantes da sua legenda, correspondem apenas às feições lineares situadas na ordem de grandeza inferior ao último táxon considerado.

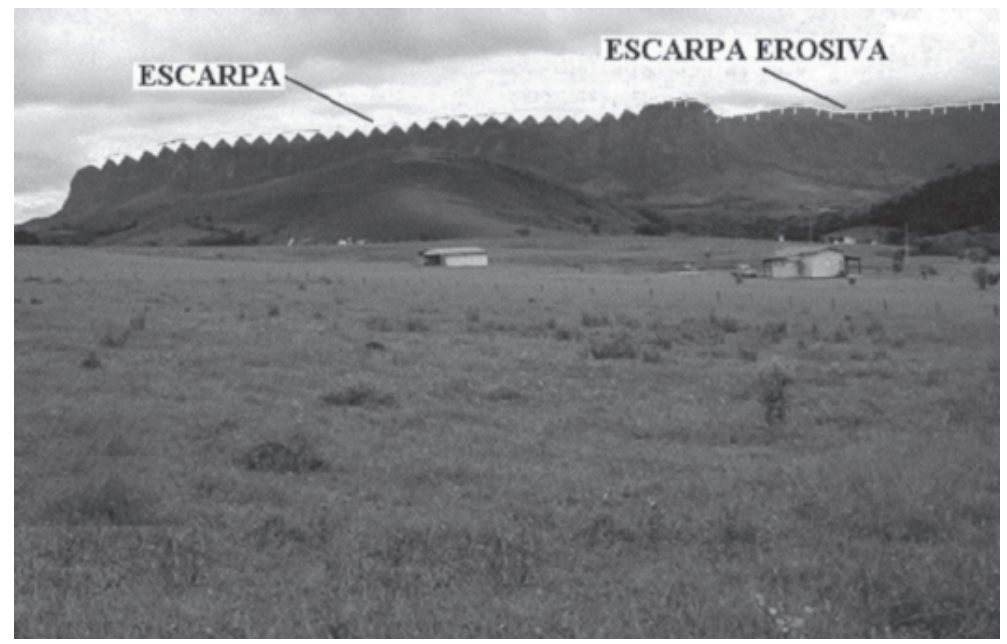

Figura 1 - Em evidência: representação gráfica da feição geomorfológica "escarpa” por meio do símbolo linear correspondente. Serra da Canastra/MG. Fonte: SOUZA (2006)

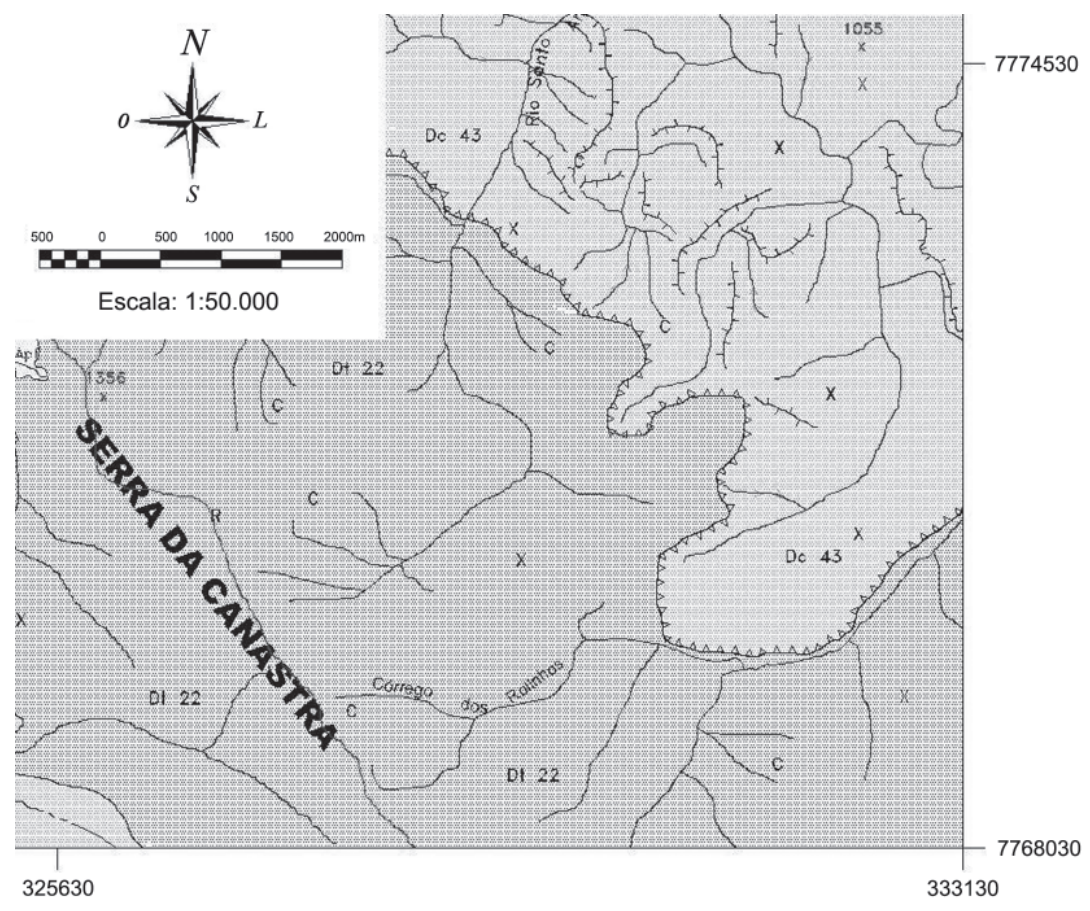

Figura 2 - Ensaio Cartográfico Utilizando-se de Linhas Simples e Complexas da Região da Serra da Canastra/MG. Detalhe de Formas de Relevo do Planalto Dissecado da Serra da Canastra evidenciando o escarpamento nas bordas da serra.

Fonte: SOUZA, (2006) 


\section{Considerações Finais}

A cartografia de um modo geral apresenta atualmente um vácuo de padronização sobre simbologia e esquemas de representação a nível nacional. Nos eventos relacionados sobre geomorfologia, são levantados constantemente questionamentos a respeito da necessidade de montar uma comissão de discussão sobre cartografia geomorfológica, demonstrando a urgência do tema, bem como a necessidade explicitada pela maioria da comunidade de geomorfólogos e pesquisadores que usufruem os conhecimentos geomorfológicos.

Cabe ressaltar que a questão sobre as dificuldades de normalização das convenções vai além do plano nacional estendendo-se também à cartografia geomorfológica de países mais avançados, tanto em termos de estudos conceituais quanto tecnológicos, gerando constantemente discussões a cerca do assunto.

Diante desta realidade ocorre a necessidade de desenvolver metodologias adotando softwares alternativos que possibilitem a criação de uma biblioteca digital de símbolos para serem disponibilizados aos profissionais da cartografia geomorfológica a fim de melhorar o trabalho e propiciar a padronização dos mapas, já que este é a base de toda a discussão teórica.

O emprego do software AutoCAD nas versões $14 \mathrm{e}$ 2000 no desenvolvimento de simbologia cartográfica, além de possibilitar um estudo mais avançado sobre a semiologia gráfica utilizada na cartografação geomorfológica, gera também, como produto, linhas especiais otimizadas que proporcionam a redução do tempo gasto na confecção de um mapa. Ao longo do trabalho de Ensaio Cartográfico com a utilização de "linetypes" especiais, foi possível constatar a agilidade e a versatilidade das entidades digitais, confirmando as hipóteses levantadas sobre os benefícios proporcionados pela otimização da simbologia linear.

Entre os avanços identificados durante a prática da cartografação, destaca-se a redução do tempo de execução do mapa e a facilidade de representação de determinadas feições ligadas ao modelado e aos processos morfodinâmicos das unidades geomorfológicas identificadas Ainda que sejam ressaltados os resultados satisfatórios, deve-se citar os problemas relacionados à apresentação virtual tais como: dificuldades de regeneração do desenho; distorção das linetypes nas curvaturas dos segmentos; conflitos entre os limites lineares e as hachuras e problemas de apresentação impressa da simbologia linear destacando a necessidade de reajustes na escala e forma das linhas para apresentação impressa. Sendo assim, a pesquisa segue sendo aprofundada na medida em que vão surgindo restrições operacionais quanto ao uso e aplicação da simbologia linear.

\section{Referências Bibliográficas}

BRASIL. Ministério das Minas e Energia. Secretaria Geral. Projeto RADAMBRASIL - Levantamento de Recursos Naturais. Rio de Janeiro, v.29, 1982. 1 mapa, color. Folha SD.23/Brasília; Escala 1:1.000.000.

BRITO. L. S.; ROSA, R. Introdução aos Sistemas de Informação Geográfica. Revista Sociedade \& Natureza. Uberlândia, 6 (11 e 12), p. 61-78, jan./dez. 1994.

DEMEK, J. (Ed) Manual of detailed geomorphological mapping. Praga, IGU, Comm Geomorph. Surv. Mapping, 1972. $368 \mathrm{p}$.

FANIRAN, A.; JEJE, L.K. Humid Tropical Geomorphology. London, 1980.

FERREIRA, I. L. Cartografia geomorfológica sob diferentes aspectos metodológicos: uma abordagem comparativa da simbologia cartográfica. 58 p. Monografia (Graduação em Geografia) - Instituto de Geografia. Universidade Federal de Uberlândia, Uberlândia, 2003.

MERCERJAKOV J.P. Les concepts de morphostruture et de morphoesculture: un nouvel instrument de l'analyse geomorphologique. Annales de Geographie, Paris, n. 423, p. 539-552, set./out. 1968.

RODRIGUES, S. C. Análise Empírico-Experimental da Fragilidade do Relevo-Solo no Cristalino do Planalto Paulistano: Sub-bacia do Reservatório Billings. 267p. 1998. Tese (Doutorado em Geografia Física) - FFLCH - USP, São Paulo, 1998.

ROSS, J. L. S. Geomorfologia: Ambiente e Planejamento. São Paulo: Contexto, 1996. 85p. (Repensando a Geografia).

. O registro cartográfico dos Fatos Geomórficos e a Questão da Taxonomia do Relevo. Revista do Departamento de Geografia. FFLCH-USP, São Paulo, n.6, p.17-29, 1992.

SALOME, A. L., VAN DORSSER, H. J. Examples of 1:50000 scale geomorphological map of part of the Ardennes. Zeitschrift fur Geomorphologie. Berlin, v. 26, n. 4, p. 481489, dez. 1982.

SIQUEIRA, C. A.; ROSA, R. Mapeamento Digital dos Aspectos Físicos da Mesorregião do Triângulo Mineiro, através dos Softwares AutoCADR12 e Grass 4.0. Revista Sociedade \& Natureza. Uberlândia, v.10 , n. 19, p. 93-114, jan./jun. 1998.

SOUZA, L. H. F., FERREIRA, I. L.; RODRIGUES, S. C. Cartografia Digital Aplicada ao Mapeamento Geomorfológico. Revista Sociedade \& Natureza, Uberlândia, v. 16, n 30 , p. 133-144, 2004.

SOUZA, L. H. F. Representação gráfica de feições lineares do relevo: proposta de aplicação de simbologia linear 
digital na cartografia geomorfológica, 91p. 2006. Dissertação. (Mestrado em Geografia) - Instituto de Geografia, Universidade Federal de Uberlândia. Uberlândia, 2006.

TRICART, J. Principles e Methodes de la Geomorphologie. Masson et Cie. Ed. Paris, 1965.
VERSTAPPEN, H. T., VAN ZUIDAM, R. A. ITC system of geomorphologic survey. ITC textbook of photo interpretation. Use of Aerial Photographs in Geomorphology by: Institute for Aerial Survey and Earth Sciences (ITC). Enschede. v. 7, 3 ed., 1975. 52p. 